\title{
Moldagem por Injeção da PA 6.6 em Moldes de Estereolitografia Metalizados com Ni-P pelo Processo Electroless
}

\author{
Diovani C. Lencina, Carlos H. Ahrens, Gean V. Salmoria, Fernando H. Lafratta \\ CIMJECT/EMC/UFSC
}

\begin{abstract}
Resumo: A fabricação de moldes por técnicas de prototipagem rápida, como a estereolitografia (SL), é considerada uma importante tecnologia no auxílio ao desenvolvimento de produtos de plástico moldados por injeção. Embora esta tecnologia se mostre vantajosa, a vida útil dos moldes pode ser bastante reduzida em decorrência, por exemplo, de forte adesão entre o polímero injetado e o material do molde SL. Neste trabalho é investigado o uso da técnica de recobrimento metálico com Ni-P por deposição electroless sobre moldes de injeção, fabricados por SL com a resina DSM SOMOS $7110^{\circledR}$. Foram comparados resultados de moldagem de PA6.6 em moldes fabricados com e sem recobrimento metálico evidenciando a possibilidade de utilizar a técnica de metalização como alternativa para a moldagem deste material em moldes SL, uma vez que a vida útil foi superior.
\end{abstract}

Palavras-chave: Moldagem por injeção de PA6.6, moldes de estereolitografia, recobrimento metálico.

\section{Injection Molding of PA 6.6 in Stereolithography Moulds Coated with Electroless Ni-P}

\begin{abstract}
Manufacturing of moulds by rapid prototyping processes, such as stereolithography (SL), is considered an important technology to aid the development of injection moulding plastic products. Although this technology shows significant advantages, the lifetime of moulds may be drastically be reduced due to strong adhesion between the injected polymer and the material of the SL mould. This work investigates the use of Ni-P metal coating obtained by electroless deposition on SL moulds manufactured with the resin DSM SOMOS 7110. Specimens of PA6.6 have been injected into SL moulds manufactured with and without metal coating. The results showed that the electroless metal coating process can be an appropriate alternative to allow moulding of small series of PA6.6 parts in SL moulds.
\end{abstract}

Keywords: PA6.6 injection molding, stereolithography molds, electroless metallic coating.

\section{Introdução}

Com o objetivo de reduzir o tempo de desenvolvimento de produtos e o custo da fabricação do ferramental, ao longo dos últimos anos tem-se desenvolvido a tecnologia de prototipagem rápida ( $\mathrm{RP}$ - Rapid Prototyping). Trata-se de um grupo de técnicas de fabricação nas quais a forma física da peça é gerada adicionando material em camadas.

A prototipagem rápida permite a produção não somente de modelos e protótipos de visualização, mas também peças funcionais, como moldes de injeção para termoplásticos. Neste caso, esta aplicação é chamada de fabricação rápida de ferramental (RT - Rapid Tooling).

Dentre as várias tecnologias de prototipagem rápida existentes, uma das mais difundidas é a estereolitografia (SL - Stereolithography), que se baseia na cura de uma resina fotossensível por um laser ultravioleta. A estereolitografia tem como principal característica a obtenção rápida e precisa de objetos tridimensionais com geometrias complexas e de bom acabamento superficial ${ }^{[1]}$.
Durante os últimos anos vários pesquisadores têm estudado a utilização da estereolitografia na área de moldagem por injeção. Alguns pesquisadores têm-se dedicado a estudar os modos de falha dos moldes SL utilizados na moldagem de plásticos por injeção ${ }^{[2-6]}$. Segundo esses autores, a força de extração pode ser considerada a principal causa do colapso dos moldes SL.

Pesquisas desenvolvidas na UFSC, relativas à injeção de termoplásticos em moldes fabricados em material polimérico, evidenciaram a importância de selecionar os materiais a serem injetados em função do material polimérico usado na fabricação do molde uma vez que a falha do molde pode também ser causada por adesão entre a peça termoplástica injetada e o molde polimérico ${ }^{[7,8]}$. Moldes de estereolitografia apresentaram grande adesividade com peças injetadas em poliamida $6.6^{[6,8]}$.

Neste trabalho, foi investigado o efeito do recobrimento de níquel-fósforo na vida útil de moldes SL, fabricados com a resina DSM SOMOS $7110^{\circledR}$, utilizados na moldagem por injeção de poliamida 6.6. 


\section{Experimental}

\section{Fabricação dos moldes}

A geometria tipo macho-fêmea (Figura 1) definida para este trabalho foi a mesma utilizada por Salmoria et al. ${ }^{[6]} \mathrm{e}$ Gonçalves et al. ${ }^{[9]}$ em seus trabalhos de investigação da resistência mecânica dos materiais usados em moldes de fabricação rápida.

Dois moldes com a mesma geometria macho-fêmea (Figura 1) foram fabricados utilizando um equipamento de estereolitografia SLA 250/30 (3DSystems, Valencia CA, EUA) com a resina DSM SOMOS $7110^{\circledR}$ (SOMOS, Heerlen, Holanda) e com os mesmos parâmetros construtivos tipicamente empregados na fabricação de moldes $\mathrm{SL}^{[10]}$. Posteriormente foram pós-curados termicamente a $100{ }^{\circ} \mathrm{C}$ em um forno elétrico (Fisher, Santa Catarina, Brasil) durante 60 minutos.

Um dos moldes (conjunto macho e fêmea) foi recoberto com uma camada de níquel-fósforo depositado por electroless, com espessura da ordem de $1 \mu \mathrm{m}$ de acordo com experimentos preliminares e comprovados por imagens de Microscopia Eletrônica de Varredura (Figura 2). Basicamen-

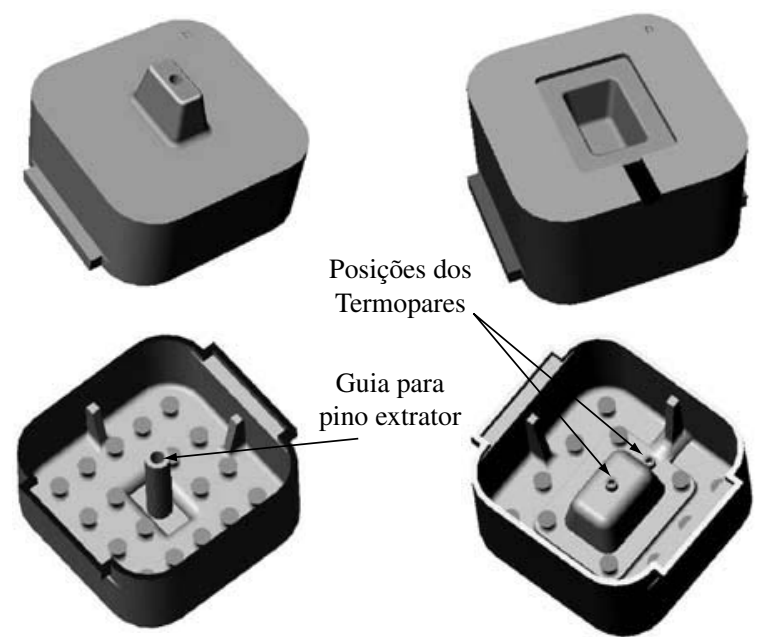

Figura 1. Ilustração da geometria tipo macho-fêmea fabricada para compor o molde indicando o posicionamento de termopares e pino extrator.

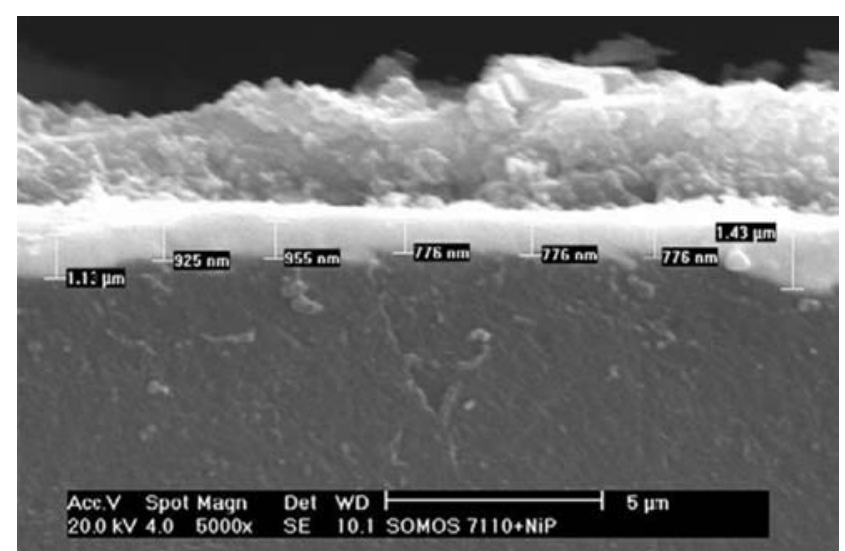

Figura 2. Imagem MEV da superfície da cavidade do molde SL (Resina DSM SOMOS $7110^{\circledR}$ ) metalizada por deposição electroless (aumento de 5000x). te, o termo electroless se deve ao fato do processo de deposição metálica sobre um substrato, a partir de uma solução aquosa, ocorrer sem o uso de uma corrente elétrica externa. $\mathrm{O}$ processo de deposição seguiu o seguinte procedimento: i) tratamento superficial; ii) ativação da superfície; iii) metalização com níquel-fósforo por electroless. O tratamento superficial consistiu, primeiramente, em um processo de lixamento com lixa d'água de grana 1000. Depois de lixados os moldes foram submetidos a um ataque químico através da imersão controlada, por 60 minutos, em uma solução aquosa a $40{ }^{\circ} \mathrm{C}$ contendo 0,17 $\mathrm{M}$ de $\mathrm{KMnO}_{4}$ e 1,24 $\mathrm{M}$ de $\mathrm{HNO}_{3}$. Posteriormente as duas partes do molde (macho e fêmea) foram lavadas em água destilada e secadas com ar. A ativação da superfície foi realizada através da imersão do molde (macho e fêmea) em uma solução aquosa contendo $\mathrm{HCl}$ (Sigma) e um ativador baseado em paládio (Noviganth AKI, Atotech $\mathrm{GmbH}$, Berlin, Alemanha) a $25^{\circ} \mathrm{C}$ por 40 minutos. Foram então mergulhados em uma solução composta de $20 \%$ de um acelerador (Noviganth AKII, Atotech GmbH, Berlin, Alemanha) diluído em água bi-destilada deionizada a $25{ }^{\circ} \mathrm{C}$. A seguir, foram imersos em um banho de metalização de níquel por electroless (Noviganth $\mathrm{Ni}$ AK Atotech $\mathrm{GmbH}$, Berlin, Alemanha) contendo: a) agente complexante; b) agente redutor baseado em hipofosfito de sódio; e c) solução baseada em $\mathrm{NiCl}_{2}$ $\left(65^{\circ} \mathrm{C}\right.$ por 15 minutos, $\left.\mathrm{pH}=7,5\right)$. Finalmente ambas as partes do molde foram lavadas com água destilada, álcool etílico e secadas em um forno a $50{ }^{\circ} \mathrm{C}$.

A Figura 3 mostra o molde (parte macho e parte fêmea) após a deposição de níquel-fósforo por electroless. Na ampliação nota-se o efeito conhecido por "degrau de escada" e a deposição satisfatória do níquel-fósforo inclusive nessas regiões, evidenciada pela ausência de regiões transparentes em decorrência de característica própria da resina de estereolitografia DSM SOMOS $7110^{\circledR}$ utilizada para a fabricação do molde.

Após a deposição de níquel-fósforo por electroless dois termopares tipo k (Minipa, São Paulo, Brasil) foram posicionados no fundo da cavidade e no meio do canal de alimenta-

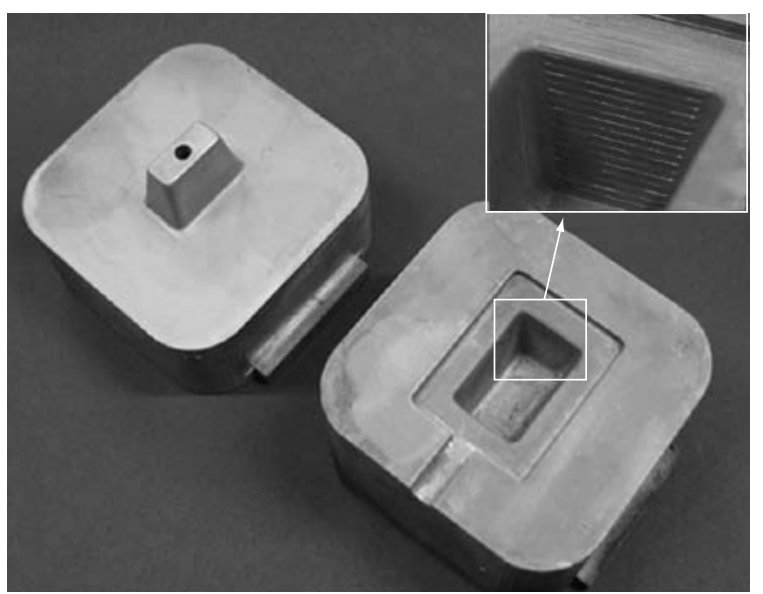

Figura 3. Conjunto de moldes após a deposição de níquel-fósforo por electroless. 


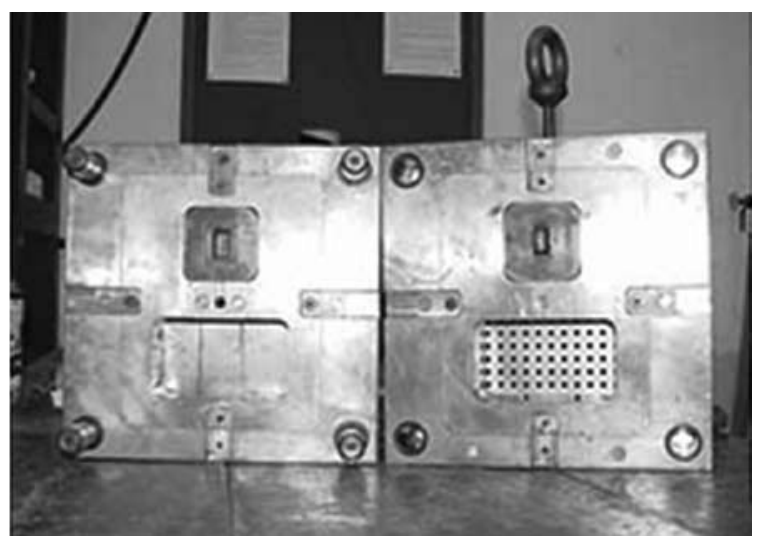

Figura 4. Molde-fêmea (esquerda) e molde-macho (direita) montados no conjunto porta-molde.

Tabela 1. Parâmetros de injeção utilizados no processo de moldagem das peças em PA6.6.

\begin{tabular}{lc}
\hline \multicolumn{1}{c}{ Parâmetros } & Valores utilizados \\
\hline Temperatura de injeção $\left({ }^{\circ} \mathrm{C}\right)$ & 287 \\
Velocidade de injeção $(\mathrm{mm} / \mathrm{s})$ & 31,2 \\
Pressão de injeção $(\mathrm{MPa})$ & 16 \\
Tempo de resfriamento $(\mathrm{s})$ & 5 \\
Pressão de recalque $(\mathrm{MPa})$ & 0 \\
Tempo de recalque $(\mathrm{s})$ & 0 \\
Força de fechamento $(\mathrm{kN})$ & 60 \\
\hline
\end{tabular}

ção, como indicado na Figura 1. Após o posicionamento dos termopares a parte traseira dos moldes foi preenchida com a resina Huntsman Rencast ${ }^{\circledR}$ CW436 (Huntsman, Salt Lake, EUA), formulada e manipulada segundo as recomendações do fabricante ${ }^{[11]}$.

\section{Processo de moldagem por injeção}

Depois de concluída a etapa de fabricação dos moldes estes foram cuidadosamente montados em um porta-molde conforme mostra a Figura 4.

Após o ajuste dos moldes no porta-molde o conjunto foi então montado em uma máquina injetora Arburg Allrounder 320S 50T e conectado ao sistema de aquisição TC-08 da Pico Technology Limited para medida de temperatura. Peças em PA6.6 Technyl A216 da Rhodia foram injetadas até a falha do molde com os valores de parâmetros de injeção obtidos inicialmente por simulação no software Moldflow Insight e ajustados na injetora pelo método de injeção progressiva. A Tabela 1 apresenta os valores utilizados para os moldes com e sem metalização por electroless.

\section{Resultados e Discussão}

Na moldagem de peças de PA6.6 nos moldes SL fabricados com a resina DSM SOMOS $7110^{\circledR}$ sem metalização, a falha prematura do molde ocorreu durante a injeção da segunda peça. Esta falha foi decorrente de uma forte adesão en- tre a peça injetada e a superfície do molde, em decorrência de afinidade química entre estes materiais, como comprovado em experimentos realizados por Gonçalves et al. ${ }^{[9]}$. Por outro lado, a injeção nos moldes metalizados possibilitou a moldagem de até 50 peças. A Figura 5 mostra graficamente o ciclo térmico dos moldes metalizados. No ciclo, a temperatura máxima atingida pelos moldes durante a injeção foi monitorada para se manter em torno de $73{ }^{\circ} \mathrm{C}$, ou seja, abaixo da temperatura de distorção ao calor da resina DSM SOMOS $7110^{\circledR}$ $\left(\right.$ HDT $\left.\sim 77{ }^{\circ} \mathrm{C}\right)$. O gráfico mostra também a diferença entre as temperaturas medidas nas duas regiões dos moldes, monitoradas pelos termopares, evidenciando que a região mais solicitada termicamente foi a do canal de alimentação, como já havia sido previsto por Gonçalves et al. ${ }^{[9]}$ nos resultados de simulação da temperatura da peça em software de CAE (Figura 6), cujos valores foram substancialmente maiores.

A Figura 7 mostra imagens tiradas do molde-fêmea após a moldagem por injeção das 50 peças. O lascamento do lado direito do ponto de entrada da cavidade, mostrado nas Figuras 7a e 7b teve início após a injeção de 16 peças. No lado esquerdo (Figuras 7a e 7f) o lascamento começou após a injeção de 27 peças. Acredita-se que este fenômeno pode

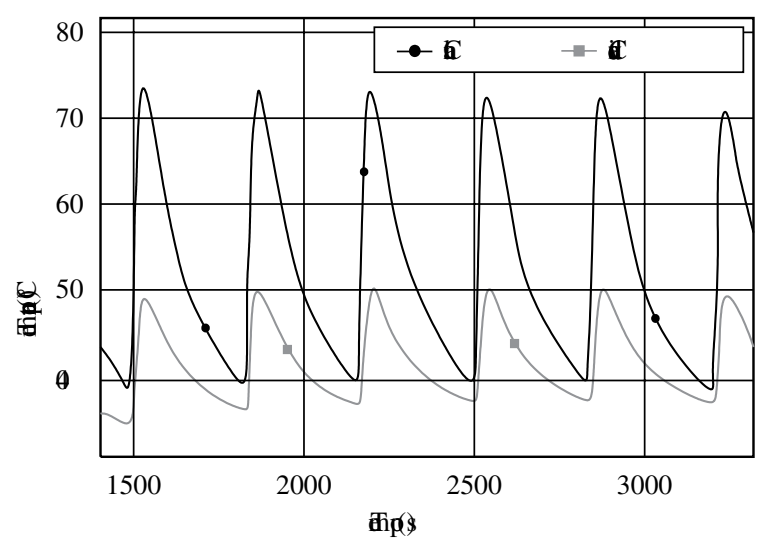

Figura 5. Ciclos térmicos para os moldes metalizados durante a injeção de PA6.6.

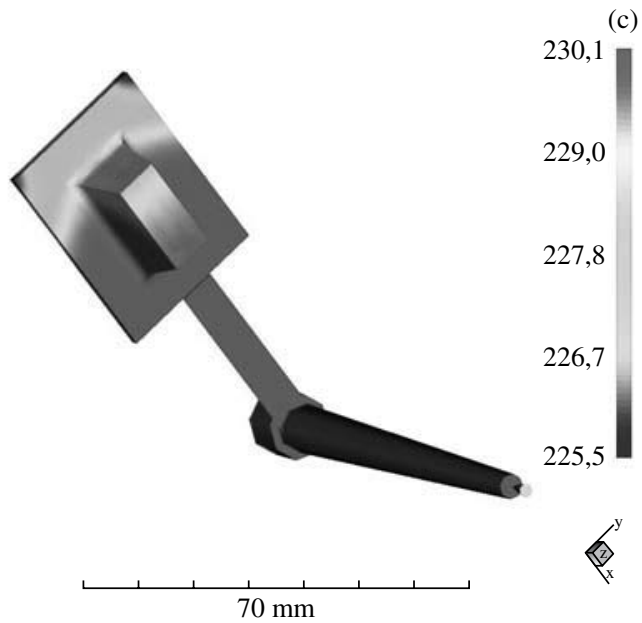

Figura 6. Resultado da simulação da distribuição de temperatura da peça na moldagem de PA6.6 em molde SL. 


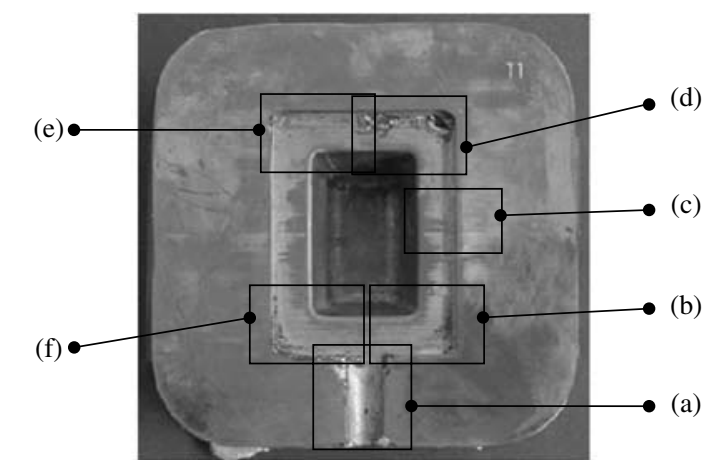

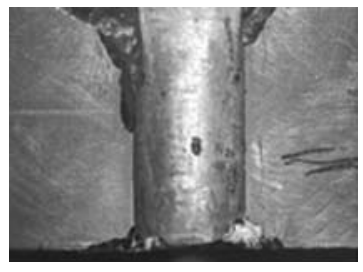

(a)

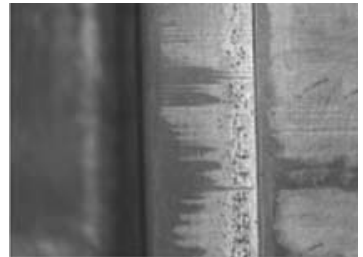

(c)

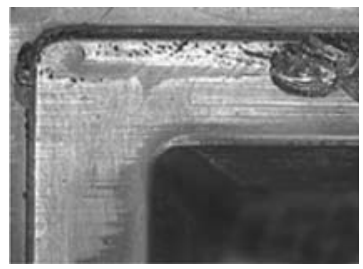

(e)

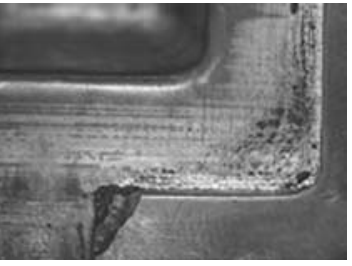

(b)

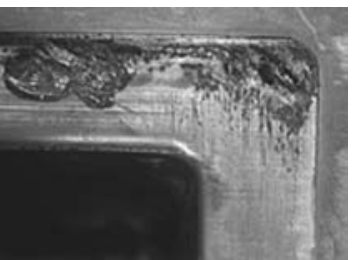

(d)

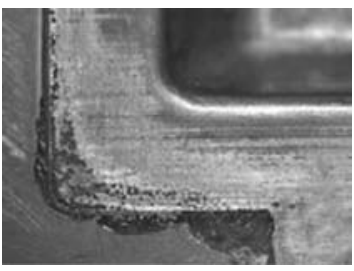

(f)
Figura 7. Molde-fêmea após a moldagem por injeção de 50 peças (todas as ampliações $=13 \mathrm{x}$ ).

ter sido causado mais devido a existência de uma região de canto vivo na geometria do molde causando sua fragilização do que algum fator decorrente de uma eventual má deposição do filme de níquel-fósforo. A delaminação observada nas Figuras $7 \mathrm{~d}$ e $7 \mathrm{e}$ ocorreu no ponto de encontro de duas frentes de fluxo (linha de solda), após a moldagem de 42 peças, podendo ser atribuída a uma eventual má deposição do filme de níquel-fósforo na região.

A Figura 8 mostra imagens tiradas do molde-macho após a injeção das 50 peças. A Figura 8a, correspondente à região do canal de alimentação, mostra uma pequena delaminação observada após a injeção de 40 peças. A Figura 8 b representa uma pequena deformação plástica do molde, decorrente de uma falha de montagem e ajuste dos moldes SL no portamolde, que ocasionou rebarbas nas peças após a moldagem de 20 peças. As rebarbas foram eliminadas aumentando-se a força de fechamento do molde de $60 \mathrm{kN}$ para $70 \mathrm{kN}$.

Já nas Figuras 8c e 8d observa-se um pequeno ponto de delaminação, iniciado após a injeção de 45 peças, na região equivalente à mostrada nas Figuras 7d e 7e. Por último, na região do pino extrator, correspondente às Figuras $8 \mathrm{e}$ e $8 \mathrm{f}$, observa-se um lascamento muito pequeno.

(c) (d)

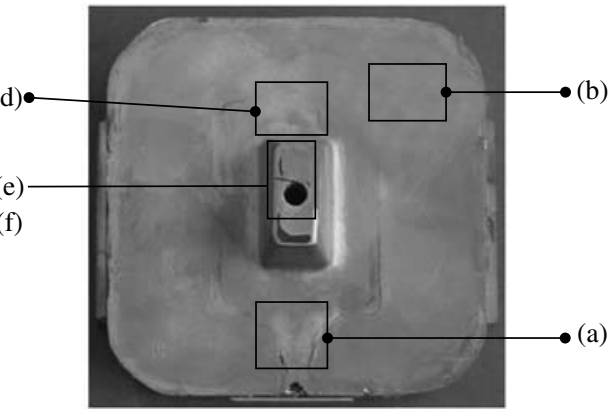

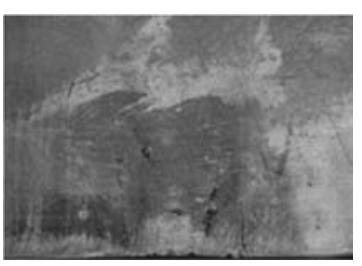

(a)

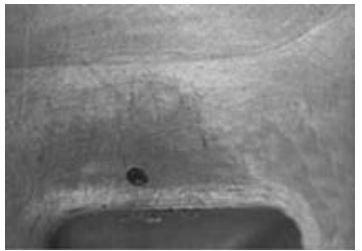

(c)

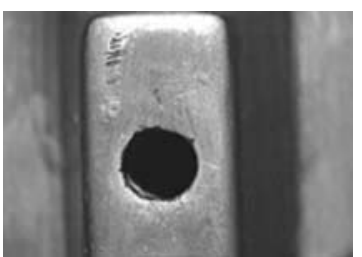

(e)

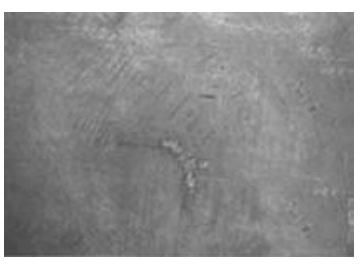

(b)

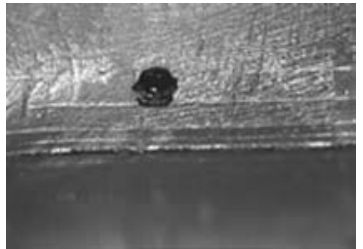

(d)

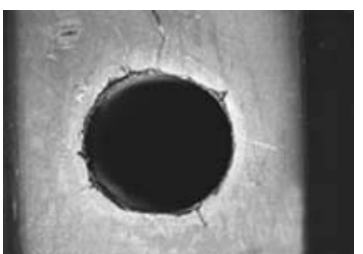

(f)
Figura 8. Molde-macho após a moldagem por injeção de 50 peças. Ampliações: a) $13 x$; b) $13 x$; c) $13 x$; d) $50 x$; e) $13 x$; e f) $25 x$

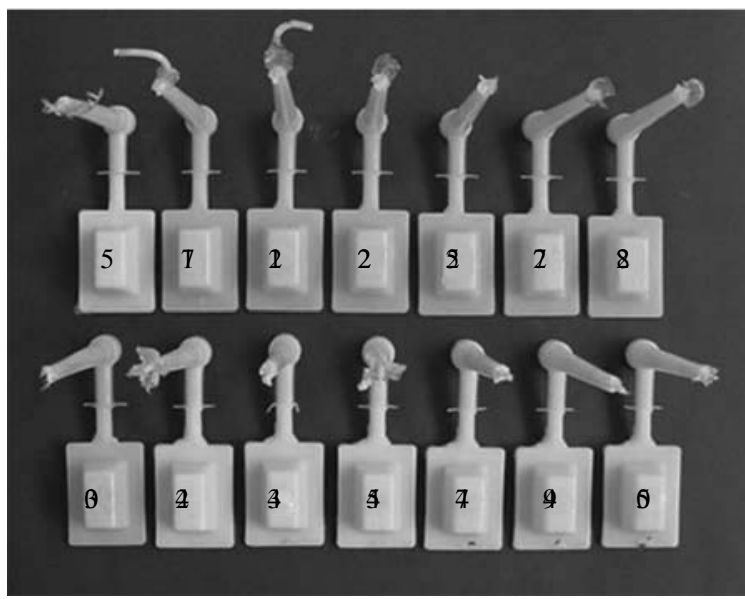

Figura 9. Amostra das 14 peças boas injetadas em PA6.6 sobre os moldes SL recobertos com níquel-fósforo depositado por electroless. 
A Figura 9 mostra 14 peças boas do total de 50 injetadas em PA6.6 onde é possível observar a modificação gradual da geometria da região do canal de entrada na peça.

\section{Conclusões}

Este trabalho mostrou que a deposição por electroless de um filme de níquel-fósforo sobre as superfícies moldantes de moldes SL fabricados com a resina DSM SOMOS $7110^{\circledR}$ possibilita a moldagem por injeção de pequenas quantidades de peças em PA6.6. Os resultados mostraram que esta técnica pode ser uma alternativa eficaz para eliminar o efeito de adesão entre a peça moldada neste material e a superfície dos moldes de SL. Embora os resultados tenham sido promissores, estes evidenciaram que regiões da cavidade do molde que apresentam cantos vivos exigem que o processo de deposição por electroless seja cuidadosamente aplicado. Experimentos com outras geometrias de moldes e estudos mais aprofundados sobre as propriedades de adesão da camada metalizada com a superfície do molde deverão ser realizados para efetivamente viabilizar no meio industrial o uso da técnica investigada neste trabalho.

\section{Agradecimentos}

Os autores gostariam de agradecer aos professores Valderes Drago e André Pasa do Departamento de Física da UFSC pelo apoio prestado durante o desenvolvimento deste trabalho.

\section{Referências Bibliográficas}

1. Wohlers, T. - "Rapid Prototyping and Tooling State of the Industry - 2003 Worldwide Progress Report", Wohlers Associates, Inc. Colorado, USA (2004).

2. Cedorge, T.; Baut, Y, Palmer, A. \& Colton, J. - "Design Rules for Stereolithography Injection Molding Inserts", in: Proceedings of the $8^{\text {th }}$ European Conference on Rapid Prototyping and Manufacturing, Nottingham, UK, p.193 (1999).

3. Colton, J.; Blair, B.M. - "Experimental Study of Postbuild Cure of Stereolithography Polymers for Injection Molds”, Rapid Prototyping Journal, 5, p.72 (1999).
4. Hopkinson, N. \& Dickens, P.M. - "'Predicting Stereolithography Injection Mould Tool Behavior Using Models to Predict Ejection Force and Tool Strength", International Journal of Production Research, 38, p.3747 (2000).

5. Ribeiro Jr, A.S. - "Proposta de utilização de ferramentas CAE no planejamento do processo de moldagem por injeção de termoplásticos em moldes de estereolitografia", Tese de doutorado, Universidade Federal de Santa Catarina, Brasil (2003).

6. Salmoria, G. V.; Pires, A. T. N; Busato, F. \& Ahrens, C. H. - "Análise de falhas em moldes fabricados por estereolitografia com a resina SOMOS 7110 e utilizados na injeção de PP e PA6.6", in: Anais do $7^{\circ} \mathrm{CBPOL}$ - Congresso Brasileiro de Polímeros, Belo Horizonte - MG, (2003).

7. Foggiatto, J. A.; Ahrens, C. H.; Salmoria, G. V. \& Pires, A. T. N., - "Moldes de ABS construidos pelo processo de Modelagem por Fusão e Deposição para injeção de PP e PEBD", Polímeros: Ciência e Tecnologia, 14, p.349 (2004)

8. Gonçalves, M. W.; Pouzada, A. S.; Salmoria, G. V. \& Ahrens, C. H. - "Performance and friction properties of injection hybrid moulds with stereolithography moulding zones", Materials Science Forum, 514-516, p.1673 (2006).

9. Gonçalves, M. W.; Rebonato, A. L.; Pires, A. T. N.; Ahrens, C. H. \& Salmoria, G. V. - "Determination of mechanical behavior of stereolithography resins used in rapid tool for injection molding", in: Proceedings of PPS-2004 Americas Regional Meeting Symposia, Florianópolis - SC, Nov (2004).

10. Gomide, R.B. - "Fabricação de Componentes Injetados com uso de Moldes de Resina Termofixa Produzidos por Estereolitografia", Dissertação de Mestrado, Universidade Federal de Santa Catarina, Brasil (2000).

11. Huntsman Rencast ${ }^{\circledR}$ CW436, Product Data Sheet (2002).

Enviado: 01/09/06

Reenviado: 07/12/06

Aceito: $27 / 12 / 06$ 